\title{
Exposure to bisphenol A in Canada: invoking the precautionary principle
}

\author{
Laura N. Vandenberg PhD
}

$\mathrm{O}$ ver the past few years, scientists, ${ }^{1}$ environmental advocates, regulatory agencies ${ }^{2}$ and the mainstream press have given much attention to the possible harm to health posed by bisphenol A. Bisphenol A is one of the most manufactured chemicals worldwide - more than three million tonnes of it are produced each year - and human exposure throughout the developed world is thought to be ubiquitous.

Because bisphenol A has estrogenic properties in vitro and in vivo, there are concerns that perinatal exposure to the chemical can alter the development of several organs and organ systems. ${ }^{3.4}$ Animals exposed to low doses of bisphenol A during the perinatal period showed malformations or altered development of the male and female reproductive tracts, the mammary glands and the brain. These animals also displayed abnormal behaviours, had reduced fertility and often became obese or showed symptoms of metabolic syndrome ${ }^{5.6}$ Bisphenol A predisposed rodents to cancer of the prostate and breasts, and increased the sensitivity of some of the animals to carcinogens. ${ }^{6,7}$ These effects were seen when animals were exposed to concentrations of bisphenol A similar to the levels to which humans are exposed. ${ }^{48}$

As an ingredient of polycarbonate plastics, bisphenol $\mathrm{A}$ is found in consumer products such as baby bottles, reusable water bottles, sports equipment, the lenses of eyeglasses, compact discs and implantable medical devices. ${ }^{8}$ It is also a component of the epoxy resins that coat the insides of food and beverage cans and of the resins used in some plastic water pipes, dental sealants and paints. Recent studies have shown that bisphenol $\mathrm{A}$ is present in or on a wide variety of papers and cardboards, including cash register receipts, papers used for wrapping food, cigarette filters and American banknotes. ${ }^{8-11}$ Studies have clearly shown that bisphenol A leaches from consumer products under normal conditions of use, and that high temperatures and exposure to acidic or basic solutions can increase the amount of bisphenol A that leaches from coatings and plastics. ${ }^{8}$

A recent review examined more than 80 bio- monitoring studies that measured the concentrations of bisphenol A in human urine, blood, saliva, breast milk, and the tissues and fluids associated with pregnancy. ${ }^{12}$ These studies examined thousands of people from the United States, Japan, Korea, China, Germany, the Netherlands and other nations in the European Union. Although each of these studies reported the presence of bisphenol A and its metabolites in healthy individuals, some of the larger studies on reference populations allowed statistical comparisons to be made by age, sex and other demographic factors. ${ }^{13-15} \mathrm{~A}$ recent large-scale study examining 5476 Canadians reported that most were exposed to bisphenol A at levels similar to those that have been described elsewhere. ${ }^{16}$ This study, the largest conducted to date, provides us with the opportunity to compare subpopulations and to consider the relevance of current levels of human exposure.

\section{Exposure in Canada}

In the Canadian study, urine samples were collected from 5476 people, and total bisphenol A (unconjugated bisphenol $\mathrm{A}$ and its metabolites) was measured using gas chromatography and tandem mass spectrometry with negative chemical ionization, a highly sensitive and selective method (limit of detection $0.2 \mathrm{ng} / \mathrm{mL}$ ). ${ }^{16}$ Of the samples examined, $90.7 \%$ had detectable levels of bisphenol A, with a geometric mean concentration of $1.16 \mathrm{ng} / \mathrm{mL}$. When the samples were separated by age, children and adolescents had higher rates of detection and geometric means than adults; of all of the age groups examined,

\section{- KeY POINTS}

- Canadians are widely exposed to bisphenol A, which likely happens when the chemical leaches from food packaging and cans.

- Thermal papers, air and dust are also possible sources of exposure.

- The levels of bisphenol A that have been detected in human tissues and fluids are similar to those that have been shown to cause permanent harm to animals.

- Canada is the first country to declare bisphenol A a health hazard, but additional regulatory action has yet to be taken.
Competing interests: None declared.

This article was solicited and has been peer reviewed.

Correspondence to: Laura N. Vandenberg, laura.vandenberg@tufts.edu

CMAJ 2011. DOI:10.1503 /cmaj.101408 
adolescents had the highest concentrations (geometric mean $1.50 \mathrm{ng} / \mathrm{mL}$ ). Among adults, detection rates and geometric mean concentrations decreased with age, and men had significantly higher concentrations than women. Several other demographic factors, including level of education and household income, also showed an association with urine concentrations of bisphenol A; interestingly, people in the intermediate range for both of these demographic factors had higher concentrations of bisphenol A than people in either the higher or lower levels of education and income.

To account for differences in urine volume, urine bisphenol A concentrations were adjusted for creatinine level. ${ }^{16}$ Adjustment for creatinine is a standard method of correcting for volume of urine, although it does have limitations. Very dilute samples with low creatinine levels could yield inaccurate results; ${ }^{17}$ however, this method remains favoured over other possible adjustments. After adjustment, the overall geometric mean concentration was $1.40 \mu \mathrm{g} / \mathrm{g}$ creatinine. The highest adjusted urine concentrations were found among children, followed by adolescents and adults, among whom the concentrations continued to decrease with age. Women had higher adjusted urine concentrations than men.

\section{Canadian levels in perspective}

The Canadian biomonitoring study reported a rate of detection of just over $90 \%,{ }^{16}$ which is similar to the rate of $92.6 \%$ reported in the American study. ${ }^{13}$ Both of these rates are higher than the rate reported in the Chinese study $(50 \%),{ }^{15}$ but lower than the rate seen among German children (99\%). ${ }^{14}$ Although comparisons of measured concentrations can be made across populations, this must be done with caution owing to differences in sampling, in the analytical methods used and in the sensitivity of the assays. For example, the American study used solid-phase extraction coupled with isotope dilution and high-performance liquid chromatography with tandem mass spectrometry (limit of detection $0.4 \mathrm{ng} / \mathrm{mL}),{ }^{13}$ the Chinese study used highperformance liquid chromatography (limit of detection $0.31 \mathrm{ng} / \mathrm{mL}),{ }^{15}$ and the German study used multidimensional liquid chromatography with tandem mass spectrometry (limit of detection $0.25 \mathrm{ng} / \mathrm{mL}) .^{14}$

In addition, there were minor discrepancies in how the data were grouped in each of these studies. For example, in the Canadian study, adults were grouped by age into several blocks, each spanning two decades; in the American study, the adults were divided into two age groups.
However, the data still collectively point to some important trends. In Canada and the US, unadjusted urine concentrations were highest among adolescents. Adjusted urine concentrations of bisphenol A usually showed a correlation with age, and among each of the age groups, concentrations were highest in the US, followed by Germany and Canada. The lowest concentrations of bisphenol A were seen in China (Figure 1 and Appendix 1, available at www.cmaj.ca /lookup/suppl/doi:10.1503/cmaj.101408/-/DC1).

These data indicate that children and adolescents have the highest urine concentrations of bisphenol A, which could be due to differences in exposure between children and adults. Children and adolescents may be at an increased risk of exposure because they are more likely than adults to use products containing bisphenol A (such as baby bottles and children's toys) and to consume goods that are packaged in products containing bisphenol A (such as canned foods). Children and adolescents also typically eat more than adults relative to their body masses. Alternatively, the age-related disparities in urine concentrations could be due to differences in the metabolism and excretion of bisphenol A. Studies in animals showed that age, sex and physiologic changes due to pregnancy all influenced the metabolism of bisphenol A. ${ }^{18,19}$

These data also suggest that human exposures to bisphenol A in the developed world, including the US, Canada and Europe, are ubiquitous (Figure 1 and Appendix 1). Studies that looked at populations in Japan and Korea support this conclusion. ${ }^{20,21}$ Although one large reference study suggested that detection rates and urine concentrations were significantly lower in developing countries such as China, ${ }^{15}$ smaller studies showed highly variable urine concentrations in these populations, ${ }^{22}$ which may indicate differences in the sources of exposure.

The comparison between concentrations measured among Canadians and Americans are particularly interesting, because these two populations are often thought of as demographically similar. Surprisingly, for each age group that was analyzed, the concentrations found among Canadians were about half those found in Americans (Figure 1 and Appendix 1). It is unlikely that the metabolism of bisphenol A differs between these two groups, so differences in the sources of exposure may account for the disparate concentrations. Because food packaging has been proposed as a major source of exposure, ${ }^{8,23}$ and because other environmental sources such as certain types of paper, air and dust have recently been identified, ${ }^{8,9}$ contact with these items is an important factor to consider when 
trying to identify plausible reasons for the differences seen in urine concentrations of bisphenol A between populations.

\section{Sources of exposure}

Many studies have measured the levels of bisphenol $\mathrm{A}$ in consumer products including polycar- bonate baby bottles, reusable food containers, food packaging and a variety of foods that have been stored in metal cans. ${ }^{8}$ These studies provide overwhelming evidence that bisphenol A leaches from consumer products under normal conditions of use.

Health Canada has conducted several studies to determine the levels of bisphenol A present in

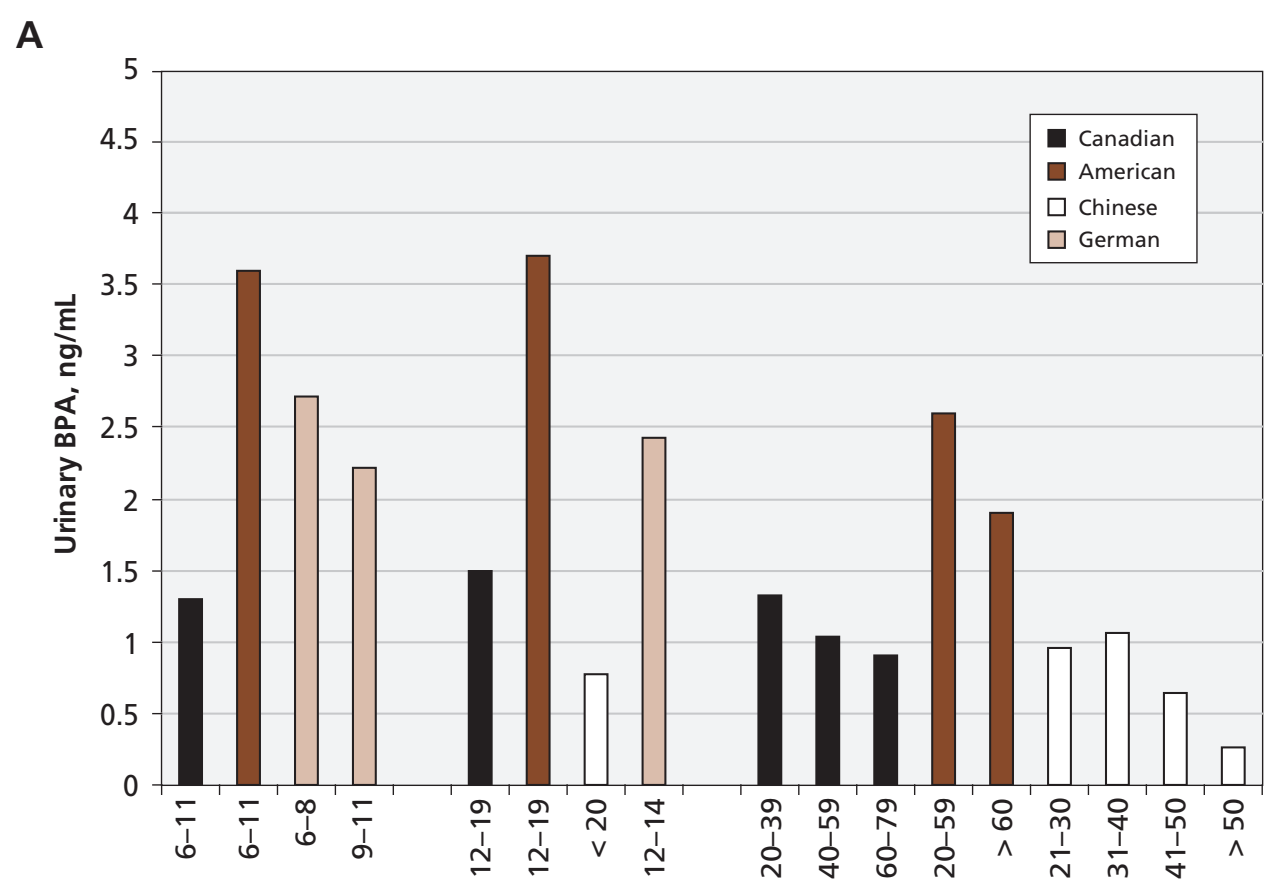

B

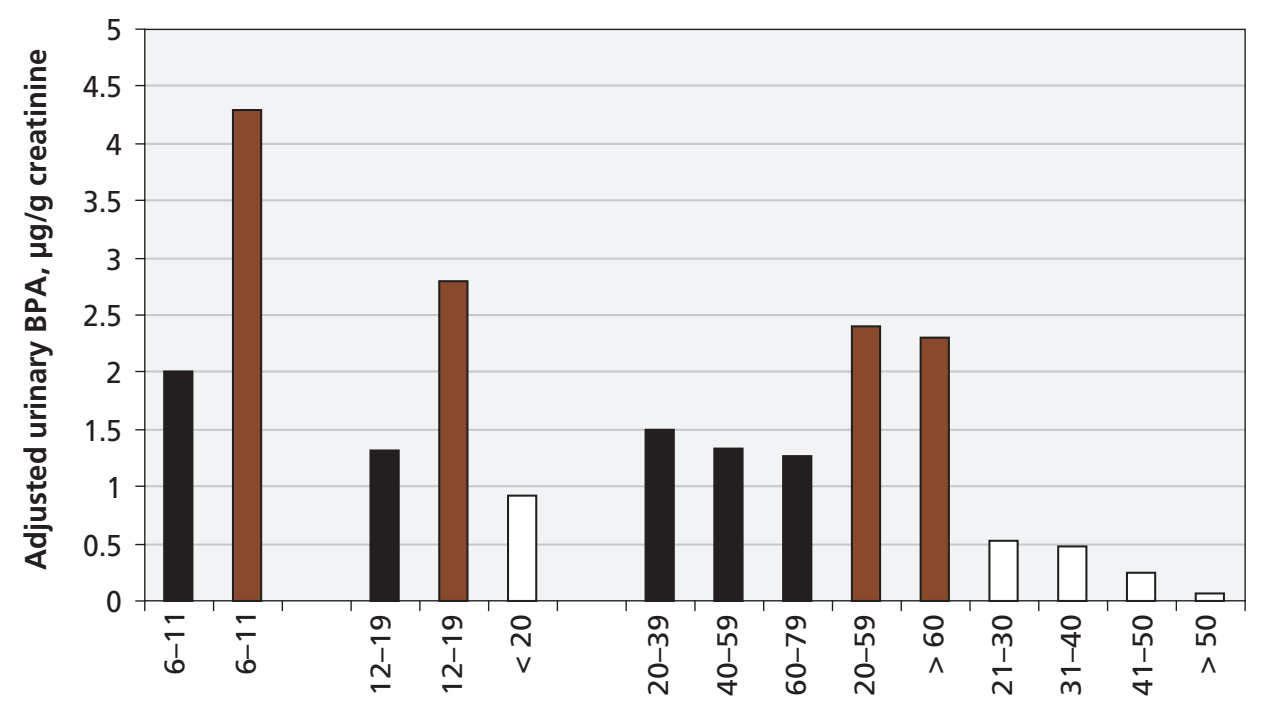

Age group, yr

Figure 1: Urine concentrations of bisphenol A in reference populations from Canada, the United States, Germany and China. (A) Unadjusted geometric mean urine concentrations by age group. (B) Urine concentrations of bisphenol A were adjusted for creatinine level to control for differences in volume of urine output. No corrected values were reported for the German reference population. BPA = bisphenol A. The data in this figure are taken from Calafet et al., ${ }^{13}$ Becker et al., ${ }^{14} \mathrm{He}$ et al. ${ }^{15}$ and Bushnik et al. ${ }^{16}$ 
a number of foods and beverages including liquid and powdered formulas for infants, baby foods packaged in glass jars with metal lids, bottled water, canned soft drinks and beer, and canned foods..$^{24,25}$ In the study of canned foods, researchers used gas chromatography and mass spectrometry to measure bisphenol A levels in 78 products available on the Canadian market. ${ }^{25}$ Bisphenol A was detected in 77 of the samples (98.7\%). Mean concentrations (standard deviations [SD]) according to type of food were as follows: tuna, 137 (173) ng/g; condensed soups, 52 (22) ng/g; ready-to-eat soups, 15 (8) ng/g; pure tomato products, $9.3 \mathrm{ng} / \mathrm{g}$; tomato pastes, $1.1(0.76) \mathrm{ng} / \mathrm{g}$; and other vegetables, 25.2 (33.5) ng/g. These levels are similar to those reported in markets in the US and Asia. ${ }^{8,26}$ Other market surveys showed that there is a high degree of variability in the amount of bisphenol A detected in the same products canned by the same manufacturer, ${ }^{27}$ which suggests that unknown factors could influence the migration of bisphenol A into canned foods.

When considering the differences in urine concentrations of bisphenol A between Americans and Canadians, we need to identify any known differences in the sources of exposure between the two populations. If food is the major source of exposure, then differences in the rates of consumption of canned foods between the two populations could explain the disparity in urine concentrations. To date, no such differences have been reported.

Another consideration is the possible difference in the composition of products between the US and Canada. Again, although this could provide a plausible explanation for the difference in concentrations seen between these two populations, there is currently no evidence to suggest that products that contain bisphenol A in the US are free of bisphenol A in Canada.

Although the ingestion of certain foods and beverages has been assumed to be the primary route for exposure to bisphenol $\mathrm{A}$, recent studies have shown that other methods of exposure may also be important. ${ }^{28}$ Several studies point to possible exposure from contact through the skin or mouth with the thermal papers used to make a variety of products such as cash register receipts. ${ }^{911}$ Bisphenol A has also been detected in a large number of environmental samples of air, dust, sewage leachates and water, ${ }^{8}$ all of which are suspected sources of exposure.

Such environmental sources may be the key to understanding the differences between the urine concentrations seen in the US and Canada. In 2008, no bisphenol A was produced in Canada, whereas almost 1 million tonnes of it were manufactured in the US. ${ }^{29}$ Thus, the en- vironmental contamination that results from the production of bisphenol A in the US may contribute to the higher levels of the chemical seen in that population.

Urine concentrations of bisphenol A in the US have risen over a relatively short period. The concentrations found in archived samples of urine collected in the US between 1988 and 1994 were remarkably similar to those recently reported in Canada (i.e., $1.33 \mathrm{ng} / \mathrm{mL}$ or adjusted concentrations of $1.36 \mu \mathrm{g} / \mathrm{g}$ creatinine).$^{30}$ Additional studies are needed to determine whether the sources of exposure in the US changed during this time but did not change in Canada, or whether these results suggest that Canadian concentrations will also rise over the next 10 20 years. Given that the current mean concentration in Canada is half that of the US, is there still cause for concern?

\section{Current exposure and risk}

Risk assessment is a complicated process typically undertaken by regulatory agencies and other panels of experts. Unfortunately, many such groups have made conflicting conclusions about the safety of human exposure to bisphenol A. ${ }^{2,6}$ The US National Toxicology Program has stated that there is some concern that bisphenol A could affect developmental outcomes in infants and neonates. The US Food and Drug Administration agrees, but also maintains that products containing bisphenol $\mathrm{A}$ are safe for use. ${ }^{31}$ In 2010, the World Health Organization (WHO) assembled a panel of experts and representatives from regulatory agencies, who concluded that there are considerable discrepancies in the results of animal studies and uncertainties about the effects of bisphenol A on human health. ${ }^{23}$ Additional reports from the WHO should be issued in 2011.

As mentioned previously, Health Canada has taken some steps to reduce the exposure of infants to bisphenol A and has recently labelled the chemical a toxic substance. ${ }^{32}$ However, Health Canada still maintains that bisphenol A is safe and does not pose any risk to the general population at the current levels of exposure. ${ }^{33}$ Regulations to remove bisphenol A from all products that come in contact with food or to ban the chemical completely are not yet forthcoming, which can be confusing to the public.

So, should health care professionals, parents and the general public be worried? Of greatest concern is that the concentrations of bisphenol A detected in human tissues and fluids - those measured among Canadians - are in the same range that were shown to cause a multitude of 
developmental problems in rodents and primates. ${ }^{5,6}$ Even low doses of bisphenol A, similar to those resulting from environmental exposures, can alter the development of the male and female reproductive tracts, the brain and the mammary glands. These same doses alter the timing of puberty, the regularity of the estrous cycle, and some of the mechanisms that control body mass and metabolism. Human epidemiologic trends over the last several decades are similar to many of the disease outcomes that have been seen in animals exposed to bisphenol $\mathrm{A}$, which has led some researchers to propose that the increased exposure of human populations to endocrine disruptors such as bisphenol $\mathrm{A}$ is responsible. ${ }^{6,7}$

\section{Knowledge gaps}

More than 100 studies have examined the effects of low doses of bisphenol A on developmental and reproductive outcomes in rodents, ${ }^{5}$ and the number of epidemiologic studies on this chemical continues to climb. In spite of substantial advances in knowledge in some areas, scientists and regulatory agencies have identified several other areas in which future research on bisphenol A should focus. ${ }^{4}$

Although much is known about some of the products that contain bisphenol $\mathrm{A}$, not all of the possible sources of contact with the chemical have been identified, and little is known about the relative contributions these sources could make to overall levels of exposure or their routes of exposure. ${ }^{8,28} \mathrm{We}$ are also currently unable to explain why there are differences in the levels of exposure between seemingly similar populations, such as Canada and the US, or why there are differences within populations according to household income, education, age and sex. ${ }^{12}$

Some small studies have measured the concentrations of circulating bisphenol A in humans, but most of these studies have examined blood samples collected in Asia and Europe. ${ }^{12}$ Determining the circulating concentrations of bisphenol $\mathrm{A}$ in the Canadian population - and in smaller subpopulations within Canada - is an important area for future study.

Finally, how quickly bisphenol A is metabolized and how its metabolism is affected by age, sex and pregnancy remains unknown., ${ }^{2}$

The sad example of human exposure to diethylstilbestrol, a potent pharmaceutical estrogen, has proven that human fetuses are extremely sensitive to exogenous hormones during early development. ${ }^{6,7}$ Some consequences of fetal exposure to diethylstilbestrol, such as breast cancer, malformed reproductive organs, infertility and other transgenerational reproductive issues, were iden- tified in rodents decades before epidemiologic studies showed that these same problems would happen in women who had been exposed to diethylstilbestrol. ${ }^{7,34}$ Epidemiologic studies currently being conducted on bisphenol $\mathrm{A}$ have linked it to several health issues, including diabetes, heart disease and behavioural problems. ${ }^{6,8,12}$ Exposure to this chemical is a concern, especially when we consider the vast literature that indicates this xenoestrogen can affect the development of rodents and primates. ${ }^{4,5}$

\section{Conclusion}

Despite the inability to identify all of the sources of exposure to bisphenol A, Health Canada has taken a unique position. It fully supports the use of precautionary approaches when considering the effects of chemicals and products on human health and environmental safety, and it has taken the first steps toward declaring bisphenol A a toxic substance. Health Canada has stated that "the potential harmful effects of bisphenol A during development cannot be dismissed and that the application of precaution is warranted." ${ }^{\prime 2}$ By invoking the precautionary principle, Health Canada has both the power and the responsibility to restrict human exposure to bisphenol A; in taking the action to label bisphenol A a toxic chemical, Health Canada must now follow through with strong legislation that will protect the Canadian public from continued exposure.

\section{References}

1. Talsness CE, Andrade AJ, Kuriyama SN, et al. Components of plastic: experimental studies in animals and relevance for human health. Philos Trans R Soc Lond B Biol Sci 2009;364:2079-96.

2. Vandenberg LN, Chahoud I, Padmanabhan V, et al. Biomonitoring studies should be used by regulatory agencies to assess human exposure levels and safety of bisphenol A. Environ Health Perspect 2010;118:1051-4.

3. Dodds EC, Lawson W. Synthetic estrogenic agents without the phenanthrene nucleus. Nature 1936;137:996.

4. vom Saal FS, Akingbemi BT, Belcher SM, et al. Chapel Hill bisphenol A expert panel consensus statement: integration of mechanisms, effects in animals and potential to impact human health at current levels of exposure. Reprod Toxicol 2007;24:131-8.

5. Richter CA, Birnbaum LS, Farabollini F, et al. In vivo effects of bisphenol A in laboratory rodent studies. Reprod Toxicol 2007; 24:199-224.

6. Vandenberg LN, Maffini MV, Sonnenschein C, et al. Bisphenol A and the great divide: a review of controversies in the field of endocrine disruption. Endocr Rev 2009;30:75-95.

7. Soto AM, Vandenberg LN, Maffini MV, et al. Does breast cancer start in the womb? Basic Clin Pharmacol Toxicol 2008;102:125-33.

8. Vandenberg LN, Hauser R, Marcus M, et al. Human exposure to bisphenol A (BPA). Reprod Toxicol 2007;24:139-77.

9. Biedermann S, Tschudin P, Grob K. Transfer of bisphenol A from thermal printer paper to the skin. Anal Bioanal Chem 2010; 398:571-6.

10. Jackson WHJ, Darnell WR, inventors. Process for foaming cellulose acetate rod. US Patent 4,507,256. 1985.

11. Schreder E. On the money: BPA on dollar bills and receipts. Seattle (WA): Washington Toxics Coalition; 2010; Available: http://watoxics.org/publications/on-the-money (accessed 2010 Dec. 21).

12. Vandenberg LN, Chahoud I, Heindel JJ, et al. Urine, serum and tissue biomonitoring studies indicate widespread exposure to bisphenol A. Environ Health Perspect 2010;118:1055-70. 


\section{ANALYSIS}

13. Calafat AM, Ye X, Wong LY, et al. Exposure of the U.S. population to bisphenol A and 4-tertiary-octylphenol: 2003-2004 Environ Health Perspect 2008;116:39-44.

14. Becker K, Göen T, Seiwert M, et al. GerES IV. Phthalate metabolites and bisphenol A in urine of German children. Int $J$ Hyg Environ Health 2009;212:685-92.

15. He Y, Miao M, Herrinton LJ, et al. Bisphenol A levels in blood and urine in a Chinese population and the personal factors affecting the levels. Environ Res 2009;109:629-33.

16. Bushnik T, Haines D, Levallois P, et al. Lead and bisphenol A concentrations in the Canadian population. Health Rep 2010;21:7-18.

17. Wolff MS, Engel SM, Berkowitz GS, et al. Prenatal phenol and phthalate exposures and birth outcomes. Environ Health Perspect 2008;116:1092-7.

18. Taylor JA, Welshons WV, Vom Saal FS. No effect of route of exposure (oral; subcutaneous injection) on plasma bisphenol A throughout $24 \mathrm{~h}$ after administration in neonatal female mice. Reprod Toxicol 2008;25:169-76.

19. Zalko D, Soto AM, Dolo L, et al. Biotransformations of bisphenol A in a mammalian model: answers and new questions raised by low-dose metabolic fate studies in pregnant CD1 mice. Environ Health Perspect 2003:111:309-19.

20. Arakawa C, Fujimaki K, Yoshinaga J, et al. Daily urinary excretion of bisphenol A. Environ Health Prev Med 2004;9:22-6.

21. Hong YC, Park EY, Park MS, et al. Community level exposure to chemicals and oxidative stress in adult population. Toxicol Let 2009;184:139-44.

22. Mao L, Cheng J-S, Hong Z, et al. Determination of environmental estrogens in human urine by high performance liquid chromatography after fluorescent derivatization with $p$-nitrobenzoyl chloride. Analytica chimica acta 2004;522:241-6.

23. World Health Organization. Joint FAO/WHO expert meeting to review toxicological and health aspects of bisphenol $A$. Geneva (Switzerland): The Organization; 2010. Available: www.who .int/foodsafety/chem/chemicals/bisphenol_release/en/index.html (accessed 2010 Dec. 1).

24. Health Canada. Survey of bisphenol A in canned food product from Canadian markets. Ottawa $(\mathrm{ON})$ : Bureau of Chemical Safety, Food Directorate, Health Products and Food Branch; 2010. Available: www.hc-sc.gc.ca/fn-an/securit/packag-emball /bpa/bpa_survey-summ-enquete-can-con-eng.php (accessed 2010 Sept. 22)

25. Cao XL, Corriveau J, Popovic S. Bisphenol A in canned food products from Canadian markets. J Food Prot 2010;73:1085-9.

26. Schecter A, Malik N, Haffner D, et al. Bisphenol A (BPA) in US food. Environ Sci Technol 2010;44:9425-30.

27. No silver lining: an investigation into bisphenol A in canned foods. Boston (MA): US PIRG; 2010. Available: www.uspirg.org/home /reports/report-archives/healthy-communities/healthy-communities /no-silver-lining-an-investigation-into-bisphenol-a-in-canned-foods (accessed 2010 Sept. 22).

28. Stahlhut RW, Welshons WV, Swan SH. Bisphenol A data in NHANES suggest longer than expected half-life, substantial nonfood exposure, or both. Environ Health Perspect 2009;117:784-9.

29. Burridge E. Chemical profile: bisphenol A. ICIS Chemical Business 2008;274:48.

30. Calafat AM, Kuklenyik Z, Reidy JA, et al. Urinary concentrations of bisphenol A and 4-nonylphenol in a human reference population. Environ Health Perspect 2005;113:391-5.

31. US Food and Drug Administration. Update on bisphenol A (BPA) for use in food: January 2010. Silverspring (MD): The Administration; 2010. Available: www.fda.gov/NewsEvents /PublicHealthFocus/ucm197739.htm (accessed 2010 Sept. 21).

32. Health Canada. Order adding a toxic substance to Schedule 1 to the Canadian Environmental Protection Act, 1999. Canada Gazette 2010;144.

33. Food and nutrition: bisphenol A. Ottawa (ON): Health Canada; 2010. Available: www.hc-sc.gc.ca/fn-an/securit/packag-emball /bpa/index-eng.php (accessed 2010 Sept. 21).

34. Newbold RR, Padilla-Banks E, Jefferson WN. Adverse effects of the model environmental estrogen diethylstilbestrol are transmitted to subsequent generations. Endocrinology 2006;147 (Suppl):S11-7.

Affiliation: Laura Vandenberg is with the Center for Regenerative and Developmental Biology, Tufts University, Medford, Mass.

Acknowledgement: The author thanks Cheryl Schaeberle for helpful comments on the manuscript.

Funding: This work was supported by the US National Institutes of Health (grant no. 1F32GM087107-01). 